\title{
Video Article \\ Prospecting Microbial Strains for Bioremediation and Probiotics Development for Metaorganism Research and Preservation
}

\author{
Helena D. M. Villela ${ }^{1}$, Caren L. S. Vilela ${ }^{1}$, Juliana M. Assis ${ }^{1}$, Natascha Varona ${ }^{2}$, Camille Burke ${ }^{2}$, David A. Coil ${ }^{2}$, Jonathan A. Eisen ${ }^{2}$, Raquel \\ S. Peixoto ${ }^{1,2,3}$ \\ ${ }^{1}$ LEMM, Laboratory of Molecular Microbial Ecology, Institute of Microbiology Paulo de Góes, Federal University of Rio de Janeiro (UFRJ) \\ ${ }^{2}$ Genome Center, University of California, Davis \\ ${ }^{3}$ IMAM-AquaRio - Rio de Janeiro Aquarium Research Center
}

Correspondence to: Raquel S. Peixoto at raquelpeixoto@micro.ufrj.br

URL: https://www.jove.com/video/60238

DOI: doi:10.3791/60238

Keywords: Bioengineering, Issue 152, microbial biodegradation, bioremediation, oil-degrading bacteria, ethinylstradiol-degrading bacteria, coral reefs, beneficial microorganisms for corals (BMCs), environmental probiotics, bioprospecting, ocean pollution, ocean conservation, oil pollution, endocrine disruptor

Date Published: 10/31/2019

Citation: Villela, H.D., Vilela, C.L., Assis, J.M., Varona, N., Burke, C., Coil, D.A., Eisen, J.A., Peixoto, R.S. Prospecting Microbial Strains for Bioremediation and Probiotics Development for Metaorganism Research and Preservation. J. Vis. Exp. (152), e60238, doi:10.3791/60238 (2019).

\section{Abstract}

Pollution affects all biomes. Marine environments have been particularly impacted, especially coral reefs, one of the most sensitive ecosystems on Earth. Globally, 4.5 billion people are economically dependent on the sea, where most of their livelihood is provided by coral reefs. Corals are of great importance and therefore their extinction leads to catastrophic consequences. There are several possible solutions to remediate marine pollutants and local contamination, including bioremediation. Bioremediation is the capacity of organisms to degrade contaminants. The approach presents several advantages, such as sustainability, relatively low cost, and the fact that it can be applied in different ecosystems, causing minimal impacts to the environment. As an extra advantage, the manipulation of endogenous microbiomes, including putative beneficial microorganisms for corals (pBMCs), may have probiotic effects for marine animals. In this context, the use of the two approaches, bioremediation and $\mathrm{pBMC}$ inoculation combined, could be promising. This strategy would promote the degradation of specific pollutants that can be harmful to corals and other metaorganisms while also increasing host resistance and resilience to deal with pollution and other threats. This method focuses on the selection of pBMCs to degrade two contaminants: the synthetic estrogen 17a-ethinylestradiol (EE2) and crude oil. Both have been reported to negatively impact marine animals, including corals, and humans. The protocol describes how to isolate and test bacteria capable of degrading the specific contaminants, followed by a description of how to detect some putative beneficial characteristics of these associated microbes to their coral host. The methodologies described here are relatively cheap, easy to perform, and highly adaptable. Almost any kind of soluble target compound can be used instead of EE2 and oil.

\section{Video Link}

The video component of this article can be found at https://www.jove.com/video/60238/

\section{Introduction}

Pollution is a major issue affecting human, animal, and plant health worldwide. Although pollution can be natural, such as volcanic ashes ${ }^{1}$, human activities are the primary cause of most pollution. Anthropogenic activities are contaminating soil, water, and air, which directly or indirectly lead to almost 20 million premature human death $s^{2}$ and decimate billions of other forms of life annually. Pollutants are present even in the most remote areas of the planet. For instance, heavy metals and persistent organic compounds have been detected in deep sea invertebrates and polar mammals, respectively ${ }^{3,4}$.

Marine environments have been especially impacted by pollution. For a long time, it was assumed that the ocean would remain unaffected and supply an endless source of goods because of its massive volume of water ${ }^{5}$. For this reason, all types of industry and institutions freely released waste in water bodies for centuries ${ }^{6,7}$. Several contaminants of all types, such as plastic ${ }^{8}$, synthetic hormones $^{9}$, pesticides $^{10}$, oil $^{11}$, nutrients $^{12}$, heavy metals ${ }^{3}$, and radioactive waste ${ }^{13}$ have been reported as impacting ocean ecosystems. In this context, coral reefs are among the most important and sensitive ecosystems in marine environments ${ }^{14}$. Reefs are coastal protectors, crucial to the development of thousands of marine species by playing essential roles in nutrients cycling and climate control. Reefs also contribute to the economy by providing fish, goods, and tourism, among others ${ }^{15}$. For instance, 4.5 billion people depend on ocean fish as their main food source ${ }^{16}$, which are greatly supported by coral reefs.

Regardless of their ecological, social, and economic importance, coral reefs are being decimated ${ }^{17,18}$. Anthropogenic activities are primarily responsible for contributing to the three main causes of corals' death: climate change, overfishing, and water pollution ${ }^{19}$. Even though it is important to work on the mitigation of global warming, it is also important to work on minimizing local contamination, including water pollution, 
that can critically contribute to coral decline ${ }^{20}$. Thus, there is an urgent need for the development of strategies to increase corals' lifetime, which could provide them with extra time to adapt and survive.

In this regard, it is extremely important to find solutions to minimize contamination and to develop strategies to increase the fitness of corals. Strategies to remediate marine pollutants are highly diverse and can be grouped into physical, chemical, and biological approaches. Physical approaches are helpful. However, they are not always efficient. For instance, plastic waste can be minimized by physical removal, while watersoluble compounds need other methodologies to be eliminated. Examples of such compounds are crude oil, released by oil industry activities and spills, as well as other micropollutants, such as synthetic hormones, normally used as the estrogenic component in oral contraceptives and present in sewage ${ }^{21,22}$. The use of chemical substances to decrease contamination can solve a specific problem, but it may also represent an extra source of pollution. This is the case with chemical dispersants to mitigate oil contamination, which have been described as even more toxic to marine ecosystems than the oil contamination itself ${ }^{23}$. For these reasons, biological approaches present several advantages when compared to the other methods. Bioremediation is the capacity of living organisms, or their metabolic products, to transform contaminants into less toxic or non-toxic forms ${ }^{24}$. The main advantages of using biological methods are sustainability, relative low cost, the fact they are ecologically friendly, and that they can be applied in different ecosystems, causing minimal or fewer impacts to the environment ${ }^{21,25,26,27}$.

Additionally, the manipulation of the microbial community present in an environment allows an extra potential advantage. There are microbiomes that are associated with hosts and are essential to their health. It is well known that these associated symbiotic microbiomes are necessary to maintain host homeostasis ${ }^{19}$. The manipulation of these associated microorganisms has been well explored for hosts such as plants and mammals $^{28,29}$, but the use of coral probiotics is still novel ${ }^{15}$. Corals also host, interact with, and depend on large and specific populations of microorganisms to survive ${ }^{19}$. The role of these microbial communities in the health and dysbiosis of corals is under active study, but it is still far from being fully understood ${ }^{30}$. One of the most popular hypotheses is called the coral probiotic hypothesis. It suggests the existence of a dynamic relationship between symbiotic microorganisms and environmental conditions which brings about the selection of the most advantageous coral metaorganisms ${ }^{31}$. Based on this information, key potential probiotic mechanisms, as well as the strategies for isolation, manipulation, and delivery of beneficial microorganisms for corals (BMCs) for several purposes, were proposed ${ }^{32}$ and tested ${ }^{33}$. These potential beneficial characteristics include resistance to temperature increase, protection from reactive oxygen species (ROS), nitrogen fixation, resistance to contaminants, and biological control against pathogens, among others ${ }^{32}$.

This study focuses on the selection of BMCs and free-living microorganisms presenting the ability to degrade two contaminants commonly found in marine environments: the synthetic estrogen 17a-ethinylestradiol (EE2) and crude oil. Pollutants containing hormone active agents are often present in water bodies $34,35,36,37,38,39,40,41,42$. Among them, synthetic estrogenic endocrine-disruptor compounds (EDCs) mimic the action of estrogens on target cells, causing several impacts on animals, including breast cancer, infertility, and hermaphroditism ${ }^{9}$. EE2 is excreted by humans because of the use of oral contraceptives. It is not removed from sewage by traditional wastewater-treatment plants and has negative effects even at very low concentrations (e.g., $\mathrm{ng} / \mathrm{L}$ or $\mu \mathrm{g} / \mathrm{L})^{43,44,45}$. Little is known about the effects of estrogens on coral physiology ${ }^{46,47}$. However, on other marine invertebrates, such as sponges, crustaceans, and mollusks, estrogens were reported to cause several negative effects mainly related to reproduction, such as development and/or stimulation of gametes, alteration in enzymatic and protein actions, problems in embryonic processes, and others $48,49,50,51,52$. The negative consequences caused by EE2 contamination highlight the necessity to develop sustainable approaches to remove this compound from the environment without impacting marine life.

In parallel, with oil currently accounting for almost $40 \%$ of the world's consumed energy sources ${ }^{53}$, chronic contamination and oil spills often occur near reef areas ${ }^{11}$. Oil contamination was reported to cause negative effects in several species of marine animals, birds, plants, and humans ${ }^{54,55,56,57}$. On corals, it causes bleaching, reduces the resistance of larvae to thermal stress ${ }^{58}$, disrupts the microbial associated communities $^{21}$, and causes tissue necrosis. In addition, chemical dispersants, an oil remediation technique commonly used by oil companies to remediate spills, are even more toxic to corals than the oil itself ${ }^{23}$. Beneficial microorganisms isolated from corals, in contrast, are known for playing crucial roles on host health. However, the manipulation of these potential probiotics must be better explored in order to investigate possible negative side effects and the metabolic capacities that can be screened to improve the fitness of the metaorganism. In this context, characteristics such as the antimicrobial activity against coral pathogens, the production of catalase to fight oxidative stress, the ability to degrade urea (which may have important roles in the calcification process), and the presence of genes that confer potential beneficial characteristics, among others, must be the focus of investigation. Here, we show how bioremediation and probiotics can be used to concomitantly mitigate the impacts of pollution and enhance coral health. The development of innovative approaches that can be used as interventions to increase marine species persistence represent a step towards a more sustainable and healthier planet.

Protocol

\section{Water and coral collection and storage for microbial isolation}

NOTE: It is essential to take the coordinates and temperature of the sampling sites. If possible, metadata such as salinity, $\mathrm{pH}$, depth, and light intensity can also help in finding fine-tuned cultivation approaches and future interpretation of data. For reliable results, keep the samples stored for the minimum length of time possible. The water/coral microbiomes may change considerably if the samples are not kept at the right temperature and/or are stored for long periods. If the isolation step is not performed instantly after collection, it is crucial to maintain samples at 4 ${ }^{\circ} \mathrm{C}$ until processing. The longer the samples are stored, even at $4{ }^{\circ} \mathrm{C}$, the more the microbial community will change.

1. Sample and store seawater.

1. Collect $500 \mathrm{~mL}$ samples of water in at least triplicate from each targeted sampling site. Preferably use sterile bottles with screw caps.

2. If processing the water instantly after collection, keep the bottles at RT for a short interval. If sample processing is happening later keep the bottles at $4{ }^{\circ} \mathrm{C}$.

2. Sample and store the coral.

1. Use a sterile pair of pliers to cut coral fragments from the same sampling site of the water samples. To avoid contamination, touch corals only with sterile gloves. 
2. Rinse the sampled coral fragment using $20 \mathrm{~mL}$ sterile saline solution ( $3 \% \mathrm{NaCl}$ in distilled water) or artificial seawater to get rid of the loosely attached free-living bacteria of the seawater.

3. Using forceps, place each coral fragment into a sterile $250-500 \mathrm{~mL}$ container with a screw cap containing sterile saline solution.

4. In the laboratory, using sterile forceps and pliers, weigh $5 \mathrm{~g}$ of coral fragments using sterile $100 \mathrm{~mm} \times 20 \mathrm{~mm}$ Petri dishes on a weighing scale.

5. Transfer the $5 \mathrm{~g}$ of coral sample to a sterile mortar and macerate it using a sterile pestle.

6. Using a sterile spatula, transfer the macerated sample to a sterile culture flask containing $45 \mathrm{~mL}$ of $3 \% \mathrm{NaCl}$ sterile solution and $10-15$ glass beads of $5 \mathrm{~mm}$. Use some of the $45 \mathrm{~mL}$ sterile saline solution to wash the mortar and recover the maximum amount of the macerate.

7. Keep the flasks under constant agitation $(150 \times \mathrm{g})$ for $16 \mathrm{~h}$ at the water temperature of the sampling site.

NOTE: For shallow-water corals the optimum temperature will range from $24-28^{\circ} \mathrm{C}$. This step will detach microorganisms from different coral compartments, such as the ones attached to the host cells, or the ones living inside the tissue and the skeleton. After this step, the coral macerates should not be stored, and the isolation step must be instantly performed.

\section{Isolation of EE2-degrading bacteria from seawater and/or corals}

1. Select bacteria.

NOTE: After steps 1.1.2 and 1.2.7, the concentration of microorganisms in seawater that have detached from the different coral macerates will be unknown and variable. In order to guarantee the isolation of individual microbial colonies in Petri dishes containing agar media, serial dilutions are needed.

1. Perform serial dilutions up to $10^{-9}$ in sterile saline solution for coral samples and up to $10^{-6}$ for water samples. Pipette dilutions up and down $5 x$ before discarding the tip. Vortex samples for $5 \mathrm{~s}$ every time before performing the next serial dilution.

2. Pipette $100 \mu \mathrm{L}$ of each dilution on Petri dishes containing $3 \% \mathrm{NaCl}$ lysogeny broth (LB) agar medium, and plate them. NOTE: Use marine agar (MA) as an alternative medium. Triplicates of each dilution are required for reliable results.

3. Incubate the plates for 1-3 days at the target temperature (e.g., $\left.26^{\circ} \mathrm{C}\right)$. Check the plates once a day.

4. Select and isolate the colonies presenting distinct growth morphologies on new plates using the streak plate technique. Repeat this step as many times as needed to have pure colonies growing on the plates.

5. If the procedure is not instantly continued to step 2.3 .1 , store isolates at $4{ }^{\circ} \mathrm{C}$ or in glycerol as described in section 2.2 .

2. Prepare glycerol stocks.

NOTE: This step is optional and can be used for long-term bacterial stocks storage.

1. Pick single colonies from the fresh plate or from the plates stored at $4{ }^{\circ} \mathrm{C}$ and independently inoculate them in $2 \mathrm{~mL}$ of sterile $\mathrm{LB}$ medium.

2. Place tubes under constant agitation $(150 \times g)$ at $24-28{ }^{\circ} \mathrm{C}$ overnight $(\mathrm{ON})$.

3. Add $1 \mathrm{~mL}$ of the bacterial cultures from step 2.2 .2 and sterile glycerol to a final concentration of $20 \%$ to the $2 \mathrm{~mL}$ cryovials.

4. Leave the cryovials $\mathrm{ON}$ at $4{ }^{\circ} \mathrm{C}$.

5. Place the glycerol bacterial stocks at $-80^{\circ} \mathrm{C}$ until needed.

3. Perform the EE2-degradation ability test.

1. Activate the isolates in LB broth or alternative media. For this, pick a single colony from the fresh plates or the plate stored at $4{ }^{\circ} \mathrm{C}$, and inoculate $2 \mathrm{~mL}$ of sterile LB medium. In case it is a glycerol stock, first streak it on LB agar plates and incubate at $24-28^{\circ} \mathrm{C}$ ON to have single colonies growing. Place the tube containing LB medium inclined under constant agitation $(150 \times g)$ at $24-28^{\circ} \mathrm{C} O \mathrm{ON}$.

2. After bacterial growth, pellet the cells by centrifuging them at $8,000 \times g$ for $8 \mathrm{~min}$ at room temperature (RT). Discard the supernatant and, gently pipetting up and down, resuspend the cells in an equal volume $(2 \mathrm{~mL})$ of saline water to wash the remaining LB broth.

3. Repeat step 2.3.2 twice to guarantee that there are no traces of carbon source, resuspending the cells in an equal volume of saline solution. For instance, if it was started with a $2 \mathrm{~mL}$ culture, resuspend the cells in a final volume of $2 \mathrm{~mL}$ saline solution.

4. Inoculate the washed and resuspended cells in minimum Bushnell Haas culture medium (BH Broth) containing EE2 as the only carbon source ${ }^{59}$

NOTE: EE2 is dissolved in ethanol at a final concentration of $5 \mathrm{mg} / \mathrm{L}$ in the culture medium. Make changes in the pollutant type and/or concentration if needed.

5. Assess bacterial growth by optical density at $600 \mathrm{~nm}$ and/or colonies forming units (CFU) on LB agar medium ${ }^{33}$, for $16-72 \mathrm{~h}$ of incubation.

NOTE: Alternatively, the microorganisms can be directly isolated on minimum media containing EE2, or other compounds, as the only carbon source. This step would direct the selection and avoid undesirable growth.

\section{Isolation of oil-degrading bacteria from seawater and/or corals}

1. Prepare minimum media containing an oil water-soluble fraction (oWSF) and oil water-insoluble fraction (oWIF) as the only carbon source ${ }^{21}$.

1. Add $1-2 \%$ crude oil to $500 \mathrm{~mL}$ of sterile distilled water. Use a filter flask opened on the bottom to take the soluble fraction out without disturbing the upper layer of the insoluble fraction.

2. Keep the mixture under constant agitation at $24-28^{\circ} \mathrm{C}$ at $150 \times g$ for $48 \mathrm{~h}$.

3. Place the filter flask containing the crude oil fractions on a stable surface and wait 10-20 min to allow soluble and insoluble fraction separation.

4. Transfer the oWSF to a new sterile flask, saving the oWIF by opening the bottom filter flask and taking out the soluble fraction.

5. Using all the oWSF recovered in the previous step $(\sim 400 \mathrm{~mL})$, prepare $1 \mathrm{~L}$ of BH agar minimum medium containing oWSF as the only carbon source. 
6. Using the oWIF remaining in the flask from step 3.1.4, prepare $1 \mathrm{~L}$ of $\mathrm{BH}$ agar minimum medium containing oWIF as the only carbon source.

2. Isolate oWSF- and oWIF-degrading bacteria.

1. Using water and coral macerate from steps 1.1 .2 and 1.2 .7 , respectively, dilute the samples up to $10^{-6}$ in sterile saline solution as described in step 2.1.1.

2. Pipette $100 \mu \mathrm{L}$ of each dilution on Petri dishes containing BH-oWSF and BH-oWIF agar media and plate them.

3. Repeat the procedures described from step 2.1.3 to step 2.1.5.

\section{Consortium member selection}

1. Extract and sequence the DNA for taxonomic identification.

1. Activate the isolates stocked in glycerol as described in step 2.3.1.

2. Extract the DNA using a DNA extraction kit (see Table of Materials).

3. Use primers 27f (5'-AGA GTT TGA TCA TGG CTC AG-3') and 1492r (5'-GTT TAC CTT GTT ACG ACT T-3') for amplification of the 16S rRNA gene.

4. Perform $50 \mu \mathrm{L}$ PCR reactions according to the following protocol: $5 \mu \mathrm{L}$ of $10 x$ polymerase buffer, $2 \mathrm{mM} \mathrm{MgCl}, 0.2 \mathrm{mM}$ dNTPs, $5 \mathrm{mM}$ of each primer, $10 \mathrm{ng}$ of genomic DNA, and $2.5 \mathrm{U}$ of Taq DNA polymerase. Add negative controls (i.e., blank DNA extractions and PCR reactions without template DNA) to ensure that there is no contamination.

5. Set up the following thermal cycling steps: a first denaturation cycle at $94{ }^{\circ} \mathrm{C}$ for $4 \mathrm{~min} ; 35$ cycles at $94{ }^{\circ} \mathrm{C}$ for 1 min, followed by $50{ }^{\circ} \mathrm{C}$ for $1 \mathrm{~min}$, and $72^{\circ} \mathrm{C}$ for $2.5 \mathrm{~min}$; a final extension cycle for $10 \mathrm{~min}$ at $72^{\circ} \mathrm{C}$.

6. Check amplicon integrity in $1.2 \%$ agarose gel using $80 \mathrm{~V}$.

7. Gel purify the samples using a gel purification kit (see Table of Materials).

8. Quantify PCR products using a fluorometer.

9. Send product for sequencing.

NOTE: For better taxonomical classifications, the Sanger method is recommended ${ }^{60}$, because it provides long sequences. The universal primers $27 \mathrm{f}$ and $1492 \mathrm{r}$ can be used to amplify nearly the entire length of the $16 \mathrm{~S}$ rRNA gene ${ }^{61}$. If contigs cannot be assembled using one pair of primers, an extra pair in the middle of the sequence should be considered.

2. Determine the growth curve.

1. Activate the isolates in glycerol stocks from step 2.2 .5 as described in step 2.3 .1 but using $5 \mathrm{~mL}$ instead of $2 \mathrm{~mL}$.

2. Add $1 \%(\mathrm{v} / \mathrm{v})$ of the grown $5 \mathrm{~mL}$ culture from step 4.2 .1 in triplicates, to a $250 \mathrm{~mL}$ flask containing $100 \mathrm{~mL}$ of $3 \% \mathrm{LB}$ media. Make sure to prepare triplicates of a negative control (no inoculum) as well.

3. Place the flasks in an incubator under constant agitation $(150 \times \mathrm{g})$ at $24-28^{\circ} \mathrm{C}$.

4. Take $1 \mathrm{~mL}$ aliquots every $4 \mathrm{~h}$ for $48 \mathrm{~h}$. If the strains present a high growth rate, decrease the $4 \mathrm{~h}$ interval.

5. Measure the optical density (OD) estimation at $600 \mathrm{~nm}$ wavelength and colony forming units (CFU) counted from serial dilutions plated on rich media plates ( $100 \mu \mathrm{L}$ should be inoculated in each plate and normalized to the volume of $1 \mathrm{~mL}$ ).

6. Plot the OD and CFU curves and analyze the correlation of OD/CFU of each individual strain. From now on, calculate the number of cells based on the OD values.

3. Perform antagonism test.

1. Activate the isolates as described in step 2.3.1.

2. Inoculate one strain at a time along the middle of plates containing agar media and the other ones perpendicular to the central one. Repeat until every selected microbial strain is tested against all others.

3. Incubate the plates at $24-28{ }^{\circ} \mathrm{C}$ and monitor them daily in order to observe potential halos indicating antagonistic activity. If halos are observed indicating antagonistic activity between two strains, one of them should be excluded.

4. Perform consortium assembly.

1. Activate the isolates as described in step 2.3.1.

2. Pellet the cells at $3,500 \times g$ and gently wash them $2 \times$ in an equal volume of saline solution. Resuspend the cells in an equal volume (i.e., if the final volume was $2 \mathrm{~mL}$ of cells, wash them using $2 \mathrm{~mL}$ of saline solution and resuspend them in a final volume of $2 \mathrm{~mL}$ ).

3. Inoculate $1 \mathrm{~mL}$ culture in $100 \mathrm{~mL} 3 \% \mathrm{NaCl}$ LB medium and incubate $\mathrm{ON}$ at $150 \mathrm{xg}$.

4. Repeat step 4.5.2, inoculate the $100 \mathrm{~mL}$ grown, washed, and resuspended cultures in $10 \mathrm{~L}$ cultures. Incubate $\mathrm{ON}$ in sterile air-lift bioreactors, receiving filtered air from a pump. If more culture is needed, always inoculate $1 \%$ of grown culture in fresh media.

5. Centrifuge grown cultures at $8,000 \times g$ for $8 \mathrm{~min}$ at $4{ }^{\circ} \mathrm{C}$. Discard supernatant after centrifugation.

6. Wash the pellet, gently resuspending the cells in $500 \mathrm{~mL}$ of sterile saline solution.

7. Repeat steps 4.5.5 and 4.5.6.

8. Resuspend each individual culture in $100 \mathrm{~mL}$ of saline solution and measure the $\mathrm{OD}$ to estimate the number of cells.

9. Calculate the volume of each culture necessary to reach a final concentration of $10^{7}$ cells $\mathrm{mL}^{-1}$.

10. Perform CFU counts on rich media for a final confirmation of cell viability and concentration.

11. Mix an equal volume of each individual culture in sterile flasks and aliquot the consortium into $50 \mathrm{~mL}$ sterile tubes.

12. Keep at $4{ }^{\circ} \mathrm{C}$ until inoculation.

NOTE: Prepare the consortium assembly as fresh as possible to guarantee cells will still be viable. Alternatively, CFU counts can be performed before inoculation. To assemble an ideal consortium, it is necessary to use isolates presenting different and complementary metabolic capacities. Usually, 6-10 isolates are used to form consortia, but this number will vary depending on the members' characteristics and purposes. 


\section{Detection of putative beneficial characteristics for corals}

1. Activate the isolates from the glycerol stocks by streaking them on $\mathrm{LB}$ agar plates and incubating them at $24-28^{\circ} \mathrm{C}$ ON to have single colonies growing. Pick a single colony from the plates and inoculate it in $2 \mathrm{~mL}$ of sterile LB medium. Place tube containing LB medium inclined under constant agitation $(150 \times g)$ at $24-28^{\circ} \mathrm{C}$ ON.

2. Perform DNA extraction as described in section 4.1 for detection of potentially beneficial genes by PCR. NOTE: PCR reaction conditions and primers will depend on the targeted gene. Methodologies to test BMC characteristics of individual strains and PCR detection for potentially beneficial genes are described in Table 1.

\section{Representative Results}

Based on the methods described here, it was possible to isolate microorganisms from different water sources and coral nubbins presenting putative BMC characteristics and capable to degrade different classes of contaminants (Figure 1). Using water samples collected at a sewage treatment plant, obtained from CESA-UFRJ (Experimental Center of Environmental Sanitation of the Federal University of Rio de Janeiro), and based on the procedure presented here, 33 bacterial strains able to degrade EE2 at a final concentration of $5 \mathrm{mg} / \mathrm{L}$ were isolated (Figure $2 \mathrm{~A}$ ). Additionally, using the technique for selecting oil-degrading bacteria, 20 strains able to degrade both oWSF (Figure 2B) and oWIF (Figure 2C) were isolated.

Putative BMC characteristics were screened in microorganisms isolated from different coral species under diverse conditions. Among them, a strain presenting strong antagonistic activity against the coral pathogen Vibrio coralliilyticus (Figure 3A), strains able to degrade urea (Figure 3B), a good catalase producer (Figure 3C), and microorganisms presenting potentially beneficial genes (Figure 3D) were found.

Employing the two approaches combined (i.e., bioremediation and BMC inoculation), it was possible to protect corals from oil exposure impacts. For this, an oil bioremediator pBMC consortium, isolated from the coral Mussismilia harttii, was inoculated on coral nubbins exposed to $1 \%$ oil in triplicates ${ }^{21}$. The treatments exposed to oil presented a progressive decrease in Fv/Fm from the fourth day onwards, reaching values close to zero by the tenth day. Variable fluorescence/maximum fluorescence (Fv/Fm) provided a measure of maximal photosystem II (PSII) photochemical efficiency of the zooxanthellae, representing an indirect measurement of coral health. On the other hand, coral nubbins present in the aquariums inoculated with the consortium showed a better-preserved photochemical ability (Figure 4).

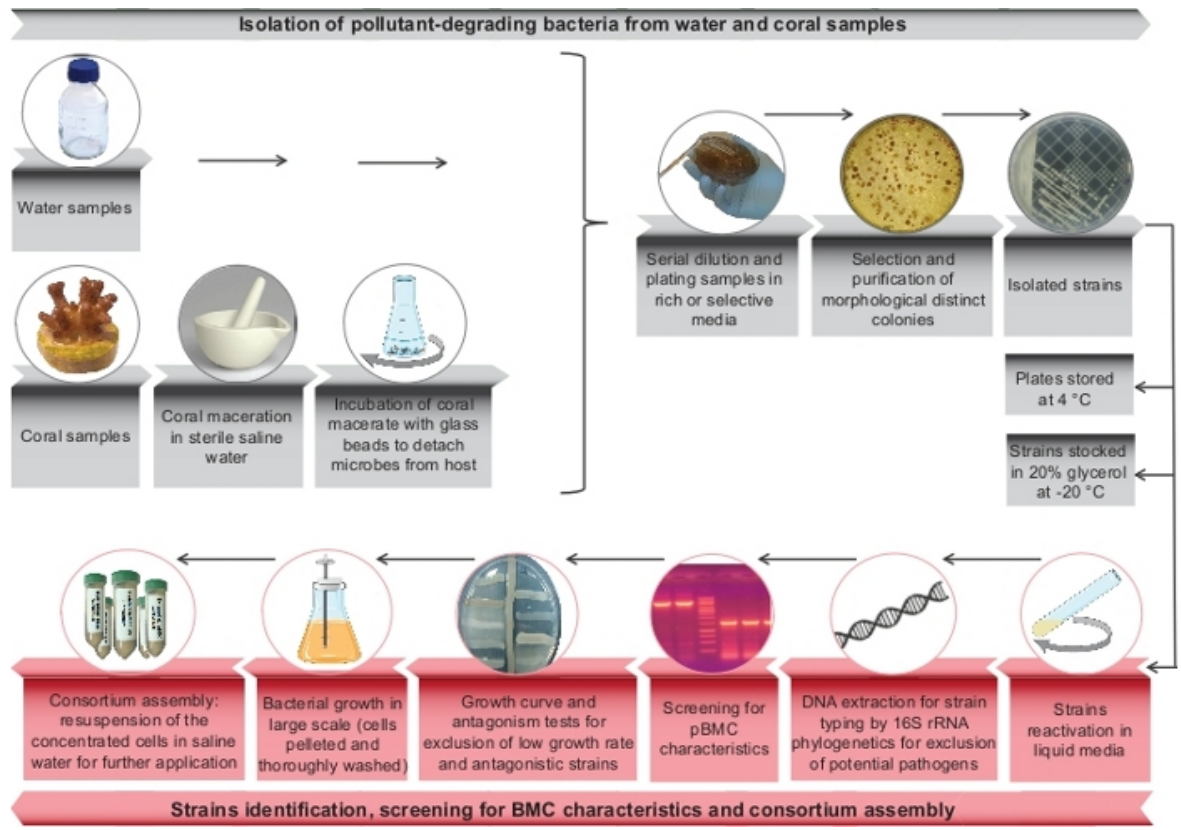

Figure 1: Summary of the main steps of a bioremediator-pBMC consortium selection and assembly. Scheme of pollutant-degrading microorganisms selection steps (in gray) and final steps used for the consortium microbial selection (DNA sequencing, growth curve, antagonism test, and consortium assembly in red). Please click here to view a larger version of this figure. 

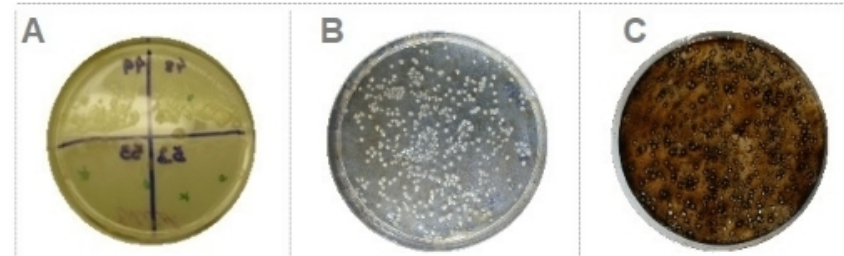

Figure 2: Selection of pollutant-degrading bacteria. (A) Bacterial isolates growing on minimum media plates containing EE2 as the only carbon source. (B) Bacteria colonies growing on minimum media plates containing oWSF as the only carbon source. (C) Bacteria colonies growing on minimum media plates containing oWIF as the only carbon source. Please click here to view a larger version of this figure.

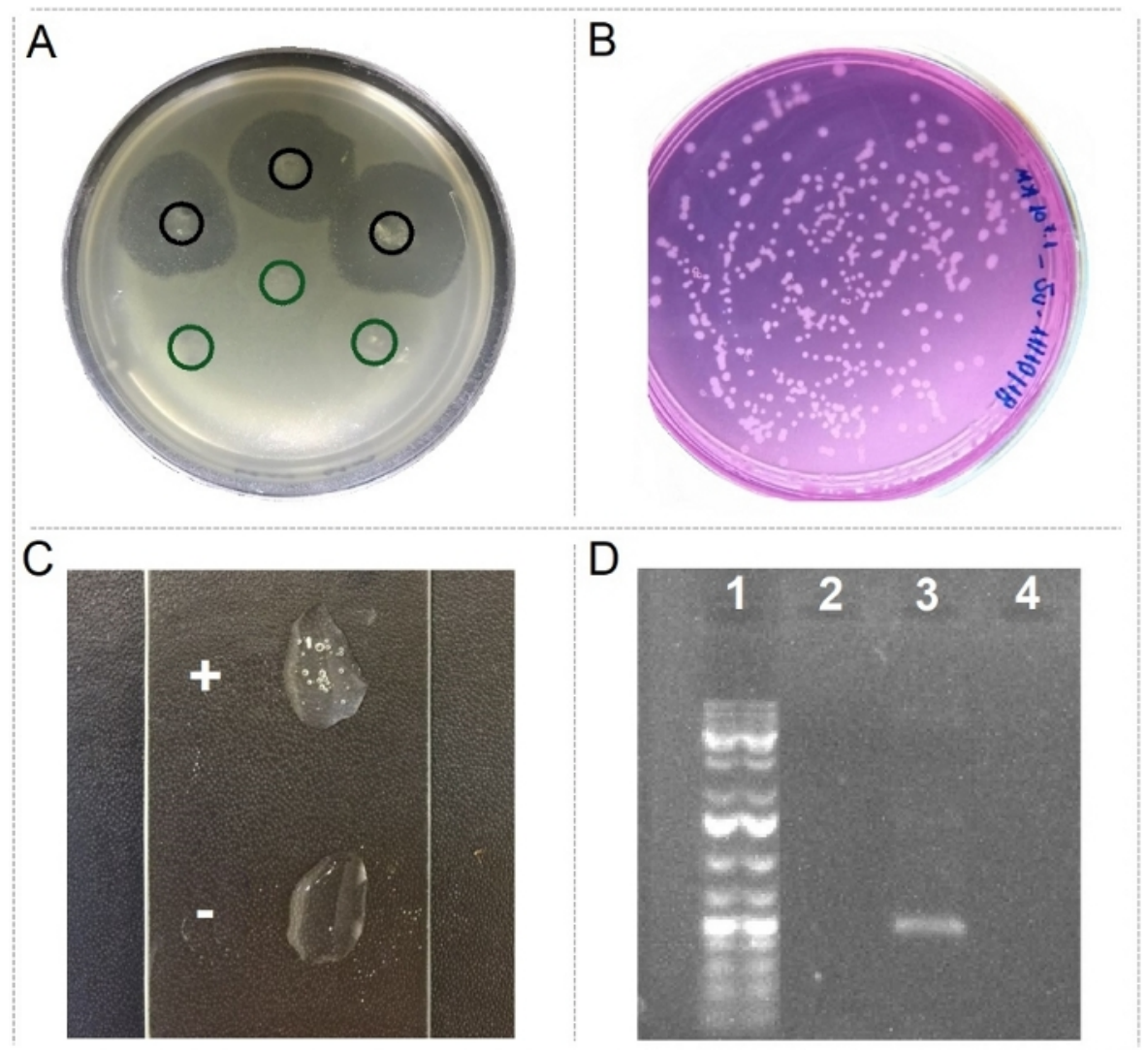

Figure 3: Detection of pBMC characteristics. (A) Spots in triplicates of strain presenting antagonistic activity against the coral pathogen Vibrio coralliilyticus (in black) and a control strain (in green). (B) Strains growing on media containing urea as the only carbon source. (C) Strain producing catalase (+) and a bad catalase producer strain (-). (D) Example of PCR detection of the nirK gene (lane $1=1 \mathrm{~kb}$ ladder; lane $2=$ blank DNA extraction negative control; lane $3=$ nirK detection; lane $4=$ PCR reactions without template DNA). Please click here to view a larger version of this figure. 


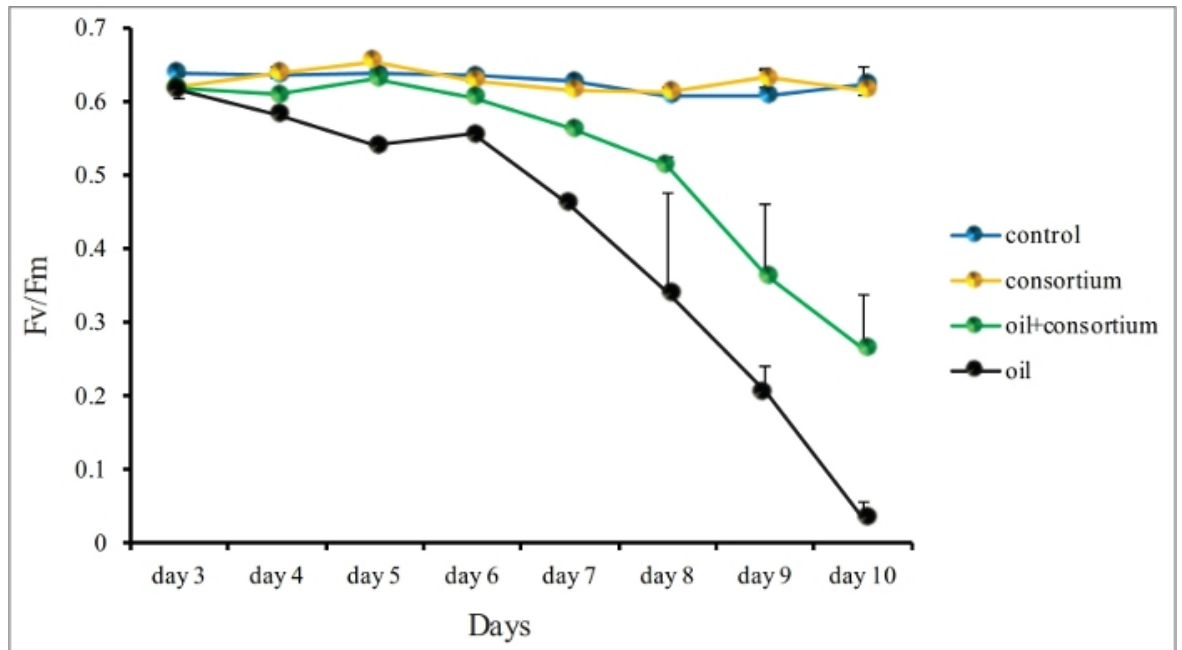

Figure 4: Fv/Fm measurements of $M$. harttii nubbins dark-adapted at 5 PM, using a diving-PAM chlorophyll fluorometer. Fv/Fm measurements of the treatments control consortium, oil, and oil with consortium were performed in triplicates every day for 10 days. Standard deviation is shown. Features of the graph were modified with permission from previous results ${ }^{21}$, available at https://www.nature.com/articles/ srep18268 under a Creative Commons Attribution 4.0. Full terms at http://creativecommons.org/licenses/by/4.0/. Please click here to view a larger version of this figure. 


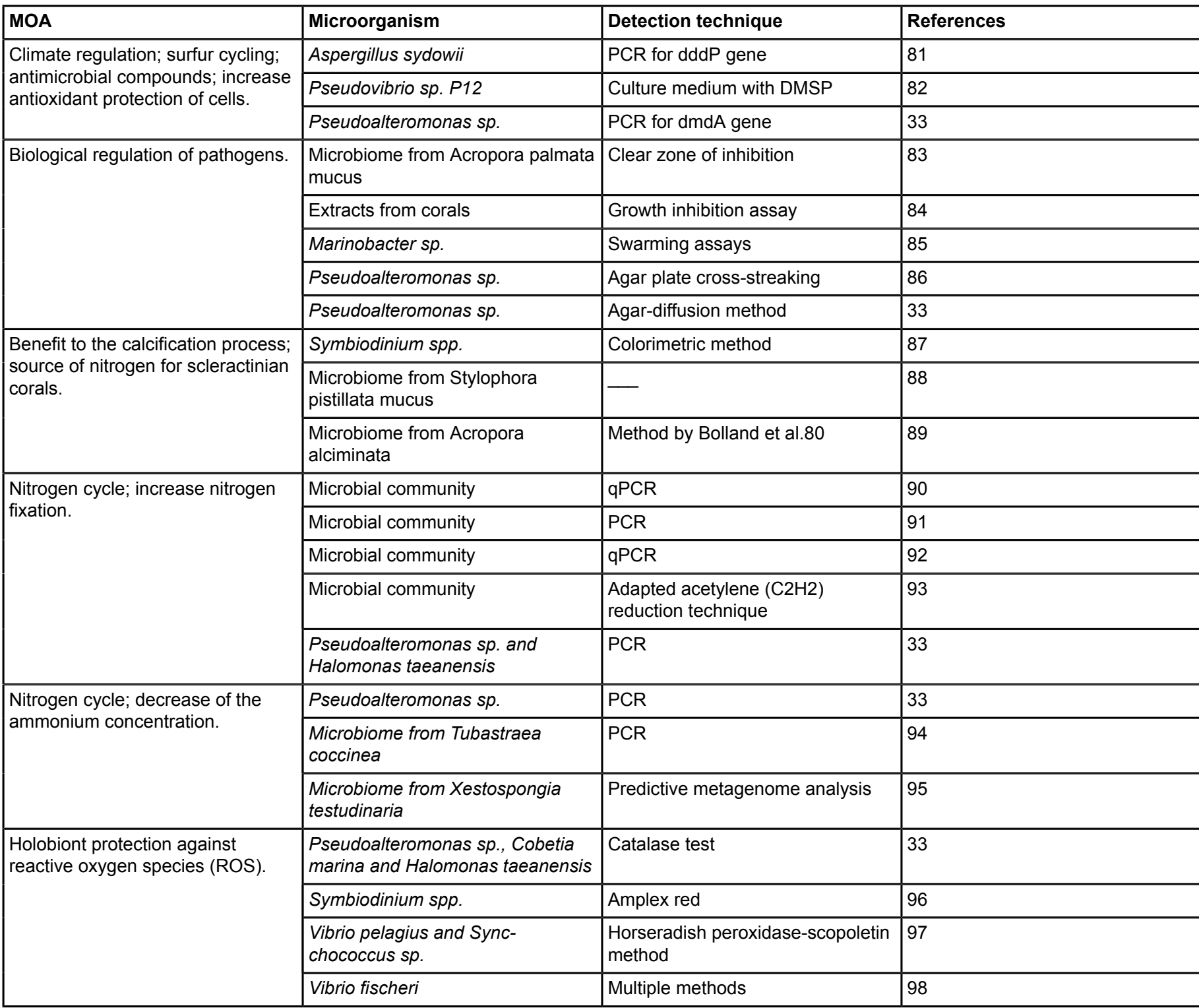

Table 1: Detection of putative BMC characteristics, mechanism of action (MOA), reported microorganisms presenting the potential and technique used to detect the characteristic.

\section{Discussion}

Bioremediation approaches have been massively explored over the past 50 years. For instance, over 200 microbes among bacteria, cyanobacteria, microalgae, and fungi in several different habitats, have been designated as able to indicate the presence and/or degrade oil hydrocarbons ${ }^{62,63,64}$. Additionally, other classes of compounds that cause impacts to the environment and to humans, such as plastic, bisphenol $\mathrm{A}$, endocrine disruptors, and heavy metals, are targets for bioremediation technique development ${ }^{65,66,67}$. On the other hand, marine probiotic development has been limited to the fields that have an obvious impact on the economy, such as fish probiotics in aquaculture ${ }^{68,69}$. However, isolation and characterization of beneficial microorganisms to protect coral reefs, marine ecosystems that support fishery, tourism, and other profitable activities, are starting to be valued ${ }^{15}$. Here, a cheap, easy, and accessible protocol to select pollutant-degrading microorganisms that can also present potentially beneficial characteristics to local marine ecosystems, especially putative beneficial microorganisms to corals (pBMCs), is described.

Additionally, the method demonstrated here is highly adaptable to several compounds and diverse types of microbial sources. It is possible to target different pollutants by replacing the only carbon source added to the minimum media. For this, instead of oil or EE2, other compounds should be added at the desired concentration. This would be the selective pressure to isolate degraders for the targeted pollutants. For instance, microorganisms capable of degrading other classes of endocrine disruptors have been already selected and tested using the same methodology ${ }^{70}$. Moreover, other marine and terrestrial organisms, such as sponges and plants ${ }^{71,72}$, as well as distinct types of environmental samples, such as soil, fuel, and rocks can be used as the degrading-microbial sources ${ }^{25,73,74}$. For instance, it was possible to detect and isolate hydrocarbon-degrading bacteria from different soil and sediment samples ${ }^{25,54,63,64,75}$. Finally, performing slight modifications in the media, 
microorganisms other than bacteria can be easily selected as the degrading-microbes. For instance, a microalgae strain with the ability to efficiently degrade estrogen compounds has been reported ${ }^{76}$.

Ideally, bioremediation-probiotic consortia must be assembled for each specific compound or area. Microbes that grow in a specific environment may not grow as well in new sites compared to their native conditions. Because researchers have not found a product that can be efficiently applied under all different environmental conditions, new consortia assembly should be performed for each specific situation. This would be akin to personalized medicine for environment-tailored recovery. For this reason, the creation of a central bank of microbial strains with potential probiotic characteristics and degradation capacity is a crucial step for the progress of this field. This initiative would save time and work, contributing to the assembly of new specific consortia worldwide.

Microorganisms associated with corals (i.e., microalgae, bacteria, archaea, fungi, and viruses) have a complex and intricate role in maintaining host homeostasis ${ }^{19}$. Environmental stressors, such as pollution, can also destabilize the coral microbiome, resulting in dysbiosis, which may cause disease and mortality ${ }^{30}$. The mechanisms by which the coral microbiome may support coral health are starting to be revealed. These mechanisms are the key to understanding coral resistance and resilience to environmental stressors and, consequently, to promote reef persistence and preservation. Additionally, findings in the field will help to understand general host-microbiome interactions, which may contribute to the development of better probiotics and health-promoting strategies in other areas. It is also important to better investigate how these probiotics inoculations can interfere on the metaorganism's health during stress events. For instance, work showing that the augmentation in coral performance is due to the probiotics and not simply the coral using bacteria as a food source are still needed.

In parallel, the development of new consortia delivery approaches and the improvement of the existing ones are of great importance. Alternative methods for consortium immobilization as well as innovative approaches, such as inoculating coral food (i.e., artemia and rotifers) and using them as vectors, are promising. These delivery systems can also be modified to target other marine organisms and will be essential to the success of the marine probiotics field.

Pollution mitigation and coral reef persistence are currently two of the main topics highlighted in environmental conferences regularly. The Agenda 2030, a document published by the United Nations that describes the global goals society should reach to allow a sustainable future, dedicates specific goals for each issue. While Goal 6 highlights the importance of water quality improvement by reducing pollution, Goal 14 reinforces the relevance of conservation and sustainable use of the oceans, seas, and marine resources ${ }^{77}$. In this context, coral reef conservation depends on changes that should be achieved in the near future, including pollution mitigation. This is of great importance, because most massive coral losses occurred when other factors were added to climate events, such as local habitat destruction and contamination ${ }^{78,79}$. This paper demonstrated that it is possible to combine bioremediation and pBMC inoculation to degrade specific pollutants, while it may increase coral's resistance and resilience to deal with pollutants and other issues. The optimization of existent protocols and/or the development of innovative methods, combined or independently applied, will be crucial to determine the future of marine ecosystems.

\section{Disclosures}

The authors have nothing to disclose.

\section{Acknowledgments}

This research was carried out in association with the ongoing R\&D project registered as ANP 21005-4, "PROBIO-DEEP - Survey of potential impacts caused by oil and gas exploration on deep-sea marine holobionts and selection of potential bioindicators and bioremediation processes for these ecosystems" (UFRJ / Shell Brasil / ANP) - "PROBIO-DEEP - Levantamento de potenciais impactos causados pela exploração de óleo e gás em holobiontes marinhos em mar profundo e seleção de potenciais bioindicadores e processos biorremediadores para esses ecossistemas", sponsored by Shell Brasil under the ANP R\&D levy as "Compromisso de Investimentos com Pesquisa e Desenvolvimento. The authors also thank Conselho Nacional de Desenvolvimento Científico e Tecnológico (CNPq) and Coordenação de Aperfeiçoamento de Pessoal de Nível Superior (CAPES) for financial support, and to Camila Messias, Phillipe Rosado, and Henrique Fragoso dos Santos, for the images provided.

\section{References}

1. Durand, M., Grattan, J. Effects of volcanic air pollution on health. Lancet. 357, 164 (2001).

2. Ramaswami, A., Russell, A. G., Culligan, P. J., Sharma, K. R., Kumar, E. Meta-principles for developing smart, sustainable, and healthy cities. Science. 352, 940-943 (2016).

3. Dökmeci, A. H., Yildiz, T., Ongen, A., Sivri, N. Heavy metal concentration in deepwater rose shrimp species (Parapenaeus longirostris, Lucas, 1846) collected from the Marmara Sea Coast in Tekirdağ. Environmental Monitoring and Assessment. 186, 2449-2454 (2014).

4. Skaare, J. U. et al. Ecological risk assessment of persistent organic pollutants in the arctic. Toxicology. 181-182, 193-197 (2002).

5. Garstang, W. The impoverishment of the sea. A critical summary of the experimental and statistical evidence bearing upon the alleged depletion of the trawling grounds. Journal of the Marine Biological Association of the United Kingdom. 6, 1-69 (1900).

6. Korajkic, A., Brownell, M. J., Harwood, V. J. Investigation of human sewage pollution and pathogen analysis at Florida Gulf coast beaches. Journal of Applied Microbiology. 110, 174-183 (2011).

7. Liu, J., Yang, W. Water sustainability for China and beyond. Science. 337, 649-650 (2012).

8. Eriksen, M. et al. Plastic pollution in the world's oceans: more than 5 trillion plastic pieces weighing over 250,000 tons afloat at sea. PLoS One. 9, e111913 (2014).

9. Vilela, C. L. S., Bassin, J. P., Peixoto, R. S. Water contamination by endocrine disruptors: Impacts, microbiological aspects and trends for environmental protection. Environmental Pollution. 235, 546-559 (2018).

10. Ueno, D. et al. Global pollution monitoring of PCBs and organochlorine pesticides using skipjack tuna as a bioindicator. Archives of Environmental Contamination and Toxicology. 45, 378-389 (2003). 
11. Villela, H. D. M., Peixoto, R. S., Soriano, A. U., do Carmo, F. L. Microbial bioremediation of oil contaminated seawater: A survey of patent deposits and the characterization of the top genera applied. Science of the Total Environment. 666, 743-758 (2019).

12. Rabalais, N. N. et al. Eutrophication-driven deoxygenation in the coastal ocean. Oceanography. 27, 172-183 (2014).

13. Calmet, D. P. Ocean disposal of radioactive waste. Status report. IAEA Bulletin. 31, 47-50 (1989).

14. Swart, P. K. Coral Reefs: Canaries of the Sea, Rainforests of the oceans. Nature Education Knowledge. 4, 5 (2013).

15. National Academies of Sciences and Medicine, E. A Research Review of Interventions to Increase the Persistence and Resilience of Coral Reefs. The National Academies Press. Washington, D.C. (2019).

16. Béné, C. et al. Feeding 9 billion by 2050-Putting fish back on the menu. Food Security. 7, 261-274 (2015).

17. Hughes, T. P. et al. Global warming and recurrent mass bleaching of corals. Nature. 543, 373 (2017).

18. Hughes, T. P. et al. Spatial and temporal patterns of mass bleaching of corals in the Anthropocene. Science. 359, 80-83 (2018).

19. Rosenberg, E., Koren, O., Reshef, L., Efrony, R., Zilber-Rosenberg, I. The role of microorganisms in coral health, disease and evolution. Nature Reviews Microbiology. 5, 355 (2007).

20. Shaver, E. C., Burkepile, D. E., Silliman, B. R. Local management actions can increase coral resilience to thermally-induced bleaching. Nature Ecology \& Evolution. 2, 1075-1079 (2018).

21. Santos, H. et al. Impact of oil spills on coral reefs can be reduced by bioremediation using probiotic microbiota. Scientific Reports. 5, 18268 (2015).

22. Whitman, W. B. Bacteria and the fate of estrogen in the environment. Cell Chemical Biology. 24, 652-653 (2017).

23. DeLeo, D. M., Ruiz-Ramos, D. V, Baums, I. B., Cordes, E. E. Response of deep-water corals to oil and chemical dispersant exposure. DeepSea Research. Part II Topical Studies in oceanography. 129, 137-147 (2016).

24. Zinicovscaia, I., Cepoi, L. Cyanobacteria for bioremediation of wastewaters. Springer. Berlin, Germany (2016).

25. Cury, J. C. et al. Microbial diversity and hydrocarbon depletion in low and high diesel-polluted soil samples from Keller Peninsula, South Shetland Islands. Antarctic Science. 27, 263-273 (2015).

26. Sinha, R. K., Valani, D., Sinha, S., Singh, S., Herat, S. Bioremediation of contaminated sites: a low-cost nature's biotechnology for environmental clean up by versatile microbes, plants, earthworms. Solid Waste Management and Environmental Remediation. 971-978 (2009).

27. Maila, M. P., Cloete, T. E. Bioremediation of petroleum hydrocarbons through landfarming: Are simplicity and cost-effectiveness the only advantages? Reviews in Environmental Science and Bio/Technology. 3, 349-360 (2004).

28. Madsen, K. et al. Probiotic bacteria enhance murine and human intestinal epithelial barrier function. Gastroenterology. 121, 580-591 (2001).

29. Saleem, M., Arshad, M., Hussain, S., Bhatti, A. S. Perspective of plant growth promoting rhizobacteria (PGPR) containing ACC deaminase in stress agriculture. Journal of Industrial Microbiology and Biotechnology. 34, 635-648 (2007).

30. Sweet, M. J., Bulling, M. T. On the importance of the microbiome and pathobiome in coral health and disease. Frontiers in Marine Science. 4 , 9 (2017).

31. Reshef, L., Koren, O., Loya, Y., Zilber-Rosenberg, I., Rosenberg, E. The coral probiotic hypothesis. Environmental Microbiology. 8, 20682073 (2006).

32. Peixoto, R., Rosado, P. M., Leite, D. C. de A., Rosado, A. S., Bourne, D. G. Beneficial Microorganisms for Corals (BMC): Proposed Mechanisms for Coral Health and Resilience. Frontiers in Microbiology. 8, 341 (2017).

33. Rosado, P. et al. Marine probiotics: increasing coral resistance to bleaching through microbiome manipulation. The The ISME Journal. 13, 921-936 (2019).

34. Heberer, T., Reddersen, K., Mechlinski, A. From municipal sewage to drinking water: fate and removal of pharmaceutical residues in the aquatic environment in urban areas. Water Science and Technology. 46, 81-88 (2002).

35. Barel-Cohen, K. et al. Monitoring of natural and synthetic hormones in a polluted river. Journal of Environmental Management. 78, 16-23 (2006).

36. Balest, L., Mascolo, G., Di laconi, C., Lopez, A. Removal of endocrine disrupter compounds from municipal wastewater by an innovative biological technology. Water Science and Technology. 58, 953-956 (2008).

37. Liu, Z., Kanjo, Y., Mizutani, S. A review of phytoestrogens: Their occurrence and fate in the environment. Water Research. 44, 567-577 (2010).

38. Chapman, H. F. et al. A national approach to health risk assessment, risk communication and management of chemical hazards from recycled water. Waterlines. 48, (2011).

39. Rocha, M. J., Cruzeiro, C., Ferreira, C., Rocha, E. occurrence of endocrine disruptor compounds in the estuary of the Iberian Douro River and nearby Porto Coast (NW Portugal). Toxicological and Environmental Chemistry. 94, 252-261 (2012).

40. Nie, M. et al. Environmental estrogens in a drinking water reservoir area in Shanghai: occurrence, colloidal contribution and risk assessment. Science of the Total Environment. 487, 785-791 (2014).

41. Ribeiro, C., Ribeiro, A. R., Tiritan, M. E. Priority substances and emerging organic pollutants in Portuguese aquatic environment: a review. Reviews of Environmental Contamination and Toxicology. 238, 1-44 (2016).

42. Wu, C., Huang, X., Lin, J., Liu, J. Occurrence and fate of selected endocrine-disrupting chemicals in water and sediment from an urban lake. Archives of Environmental Contamination and Toxicology. 68, 225-236 (2015).

43. Shi, W., Wang, L., Rousseau, D. P. L., Lens, P. N. L. Removal of estrone, 17a-ethinylestradiol, and 17ß-estradiol in algae and duckweedbased wastewater treatment systems. Environmental Science and Pollution Research. 17, 824-833 (2010).

44. Ternes, T., Bonerz, M., Schmidt, T. Determination of neutral pharmaceuticals in wastewater and rivers by liquid chromatography-electrospray tandem mass spectrometry. Journal of Chromatography A. 938, 175-185 (2001).

45. Ternes, T. A., Andersen, H., Gilberg, D., Bonerz, M. Determination of estrogens in sludge and sediments by liquid extraction and GC/MS/MS. Analytical Chemistry. 74, 3498-3504 (2002).

46. Tarrant, A. M., Atkinson, M. J., Atkinson, S. Effects of steroidal estrogens on coral growth and reproduction. Marine Ecology Progress Series. 269, 121-129 (2004).

47. Atkinson, S., Atkinson, M. J., Tarrant, A. M. Estrogens from sewage in coastal marine environments. Environmental Health Perspectives. 111, 531-535 (2003).

48. Schoenmakers, H. J. N., Van Bohemen, C. G., Dieleman, S. J. Effects of Oestradiol\#17 $\beta$ on the Ovaries of the Starfish Asterias rubens. Development Growth and Differentiation. 23, 125-135 (1981).

49. Sarojini, R., Jayalakshmi, K., Sambashivarao, S. Effect of external steroids on ovarian development in freshwater prawn, Macrobrachium lamerrii. Journal of Advanced Zoology. 7, 50 (1986). 
50. Hathaway, R. R., Black, R. E. Interconversions of estrogens and related developmental effects in sand dollar eggs. General and Comparative Endocrinology. 12, 1-11 (1969).

51. Ghosh, D., Ray, A. K. Subcellular action of estradiol-17ß in a freshwater prawn, Macrobrachium rosenbergii. General and Comparative Endocrinology. 90, 274-281 (1993).

52. Aris, A. Z., Shamsuddin, A. S., Praveena, S. M. occurrence of $17 \alpha$-ethynylestradiol (EE2) in the environment and effect on exposed biota: a review. Environment International. 69, 104-119 (2014).

53. International Energy Agency. Key World Energy Statistics (KWES). (2018).

54. Carmo, F. L. et al. Bacterial structure and characterization of plant growth promoting and oil degrading bacteria from the rhizospheres of mangrove plants. Journal of Microbiology. 49, 535-543 (2011).

55. Piatt, J. F., Lensink, C. J., Butler, W., Kendziorek, M., Nysewander, D. R. Immediate impact of the'Exxon Valdez'oil spill on marine birds. The Auk. 107 (2), 387-397 (1990).

56. White, H. K. et al. Impact of the Deepwater Horizon oil spill on a deep-water coral community in the Gulf of Mexico. Proceedings of the National Academy of Sciences of the United States of America. 109, 20303-20308 (2012).

57. Abdel-Shafy, H. I., Mansour, M. S. M. A review on polycyclic aromatic hydrocarbons: source, environmental impact, effect on human health and remediation. Egyptian Journal of Petroleum. 25, 107-123 (2016).

58. Negri, A. P., Hoogenboom, M. O. Water contamination reduces the tolerance of coral larvae to thermal stress. PLoS One. 6, e19703 (2011).

59. Brown, E. J., Resnick, S. M., Rebstock, C., Luong, H. V, Lindstrom, J. UAF radiorespirometric protocol for assessing hydrocarbon mineralization potential in environmental samples. Biodegradation. 2, 121-127 (1991).

60. Sanger, F., Nicklen, S., Coulson, A. R. DNA sequencing with chain-terminating inhibitors. Proceedings of the National Academy of Sciences of the United States of America. 74, 5463-5467 (1977).

61. Vergin, K. L. et al. Screening of a Fosmid Library of Marine Environmental Genomic DNA Fragments Reveals Four Clones Related to Members of the Order Planctomycetales. Applied and Environmental Microbiology. 64 (8), 3075-3078 (1998).

62. Yakimov, M. M., Timmis, K. N., Golyshin, P. N. Obligate oil-degrading marine bacteria. Current Opinion in Biotechnology. 18, 257-266 (2007).

63. Santos, H. F., Cury, J. C., Carmo, F. L., Rosado, A. S., Peixoto, R. S. 18S rDNA sequences from microeukaryotes reveal oil indicators in mangrove sediment. PLoS One. 5, e12437 (2010).

64. Jurelevicius, D., Cotta, S. R., Peixoto, R., Rosado, A. S., Seldin, L. Distribution of alkane-degrading bacterial communities in soils from King George Island, Maritime Antarctic. European Journal of Soil Biology. 51, 37-44 (2012).

65. Paço, A. et al. Biodegradation of polyethylene microplastics by the marine fungus Zalerion maritimum. Science of the Total Environment. 586, 10-15 (2017).

66. Zhang, W., Yin, K., Chen, L. Bacteria-mediated bisphenol A degradation. Applied Microbiology and Biotechnology. 97, 5681-5689 (2013).

67. Gadd, G. M. Metals, minerals and microbes: geomicrobiology and bioremediation. Microbiology. 156, 609-643 (2010).

68. Balcázar, J. L. et al. The role of probiotics in aquaculture. Veterinary Microbiology. 114, 173-186 (2006).

69. Gatesoupe, F. J. The use of probiotics in aquaculture. Aquaculture. 180, 147-165 (1999).

70. Ren, Y.X., Nakano, K., Nomura, M., Chiba, N., Nishimura, O. Effects of bacterial activity on estrogen removal in nitrifying activated sludge. Water Research. 41, 3089-3096 (2007).

71. Santos-Gandelman, J. F., Giambiagi-deMarval, M., Muricy, G., Barkay, T., Laport, M. S. Mercury and methylmercury detoxification potential by sponge-associated bacteria. Antonie Van Leeuwenhoek. 106, 585-590 (2014).

72. Yamaga, F., Washio, K., Morikawa, M. Sustainable biodegradation of phenol by Acinetobacter calcoaceticus P23 isolated from the rhizosphere of duckweed Lemna aoukikusa. Environmental Science \& Technology. 44, 6470-6474 (2010).

73. Soriano, A. U. et al. Microbiological aspects of biodiesel and biodiesel/diesel blends biodeterioration. International Biodeterioration \& Biodegradation. 99, 102-114 (2015).

74. Da Cunha, C. D., Rosado, A. S., Sebastián, G. V, Seldin, L., Von der Weid, I. Oil biodegradation by Bacillus strains isolated from the rock of an oil reservoir located in a deep-water production basin in Brazil. Applied Microbiology and Biotechnology. 73, 949-959 (2006).

75. Prantera, M. T., Drozdowicz, A., Leite, S. G., Rosado, A. S. Degradation of gasoline aromatic hydrocarbons by two N 2-fixing soil bacteria. Biotechnology Letters. 24, 85-89 (2002).

76. Lai, K. M., Scrimshaw, M. D., Lester, J. N. Biotransformation and bioconcentration of steroid estrogens by Chlorella vulgaris. Applied and Environmental Microbiology. 68, 859-864 (2002).

77. United Nations. Transforming our World: The 2030 Agenda for Sustainable Development. (2015).

78. Bellwood, D. R., Hughes, T. P., Folke, C., Nyström, M. Confronting the coral reef crisis. Nature. 429, 827 (2004).

79. Pandolfi, J. M. et al. Global trajectories of the long-term decline of coral reef ecosystems. Science. 301, 955-958 (2003).

80. Bolland, E. G., Cook, A. R., Turner N. A. Urea as a sole source of nitrogen for plant growth. I. The development of urease activity in Spirodela oligorrhiza. Planta. 83, 1-12 (1968).

81. Kirkwood, M., Todd, J. D., Rypien, K. L., Johnston, A. W. B. The opportunistic coral pathogen Aspergillus sydowii contains dddP and makes dimethyl sulfide from dimethylsulfoniopropionate. The ISME Journal. 4, 147-150 (2010).

82. Raina, J., Tapiolas, D., Motti, C., Foret, S., Seemann, T. Isolation of an antimicrobial compound produced by bacteria associated with reefbuilding corals. Peer J. 4, e2275 (2016).

83. Ritchie, K. B. Regulation of microbial populations by coral surface mucus and mucus-associated bacteria. Marine Ecology Progress Series. 322, 1-14 (2006).

84. Gochfeld, D. J., Aeby, G. S. Antibacterial chemical defenses in Hawaiian corals provide possible protection from disease. Marine Ecology Progress Series. 362, 119-128 (2008).

85. Alagely, A., Krediet, C. J., Ritchie, K. B., Teplitski, M. Signaling mediated cross-talk modulates swarming and biofilm formation in a coral pathogen Serratia marcescens. The ISME Journal. 5, 1609-1620 (2011).

86. Kvennefors, E. C. E. et al. Regulation of bacterial communities through antimicrobial activity by the coral holobiont. Microbial Ecology. 63, 605-618 (2012).

87. Biscere, T. et al. Enhancement of coral calcification via the interplay of nickel and urease. Aquatic Toxicology. 200, 247-256 (2018).

88. Grover, R., Maguer, J., Allemand, D., Ferrier-Pages, C. Urea uptake by the scleractinian coral Stylophora pistillata. Journal of Experimental Marine Biology and Ecology. 332, 216-225 (2006).

89. Crossland, C. J., Barnes, D. J. The Role of Metabolic Nitrogen in Coral Calcification. Marine Biology. 28, 325-332 (1974).

90. Olson, N. D., Ainsworth, T. D., Gates, R. D., Takabayashi, M. Diazotrophic bacteria associated with Hawaiian Montipora corals: diversity and abundance in correlation with symbiotic dinoflagellates. Journal of Experimental Marine Biology and Ecology. 371, 140-146 (2009). 
91. Lema, K. A., Willis, B. L., Bourneb, D. G. Corals form characteristic associations with symbiotic nitrogen-fixing bacteria. Applied and Environmental Microbiology. 78, 3136-3144 (2012).

92. Santos, H. F. et al. Climate change affects key nitrogen-fixing bacterial populations on coral reefs. The ISME Journal. 8, 2272-2279 (2014).

93. Cardini, U., et al. Functional significance of dinitrogen fixation in sustaining coral productivity under oligotrophic conditions. Proceedings of the Royal Society B: Biological Sciences. 282, 20152257 (2015).

94. Yang, S., Sun, W., Zhang, F., Li, Z. Phylogenetically diverse denitrifying and ammonia-oxidizing bacteria in corals Alcyonium gracillimum and Tubastraea coccinea. Marine Biotechnology. 15, 540-551 (2013).

95. de Voogd, N. J., Cleary, D. F. R. M., Polonia, A. R. M., Gomes, N. C. M. Bacterial community composition and predicted functional ecology of sponges, sediment and seawater from the thousand islands reef complex, West Java, Indonesia. FEMS Microbiology Ecology. 91, fiv019 (2015).

96. Suggett, D. J. et al. Photosynthesis and production of hydrogen peroxide by Symbiodinium (Pyrrhophyta) phylotypes with different thermal tolerances. Journal of Phycology. 44, 948-956 (2008).

97. Petasne, R. G., Zika, R. G. Hydrogen peroxide lifetimes in south Florida coastal and offshore waters. Marine Chemistry. 56, 215-225 (1997).

98. McFall-Ngai, M. J. Consequences of evolving with bacterial symbionts: insights from the squid-Vibrio associations. Annual Review of Ecology, Evolution, and Systematics. 30, 235-256 (1999). 